\title{
C-reactive protein in outpatients with acute exacerbation of COPD: its relationship with microbial etiology and severity
}

This article was published in the following Dove Press journal:

International Journal of COPD

21 October 2016

Number of times this article has been viewed

\author{
Miguel Gallego'-3 \\ Xavier Pomares ${ }^{1,3}$ \\ Silvia Capilla ${ }^{4}$ \\ Maria Angeles Marcos 5,6 \\ David Suárez ${ }^{7}$ \\ Eduard Monsól-3,* \\ Concepción Montón ${ }^{1,8, *}$ \\ 'Department of Respiratory Medicine, \\ Hospital de Sabadell, Institut \\ Universitari Parc Taulí-UAB, Sabadell, \\ ${ }^{2}$ Universitat Autònoma de Barcelona, \\ Esfera UAB, Barcelona, ${ }^{3} \mathrm{CIBER}$ \\ de Enfermedades Respiratorias, \\ CIBERES, Bunyola, ${ }^{4}$ Laboratory of \\ Microbiology, Institut Universitari \\ Parc Taulí-UAB, Sabadell, ${ }^{5}$ Department \\ of Clinical Microbiology, Hospital \\ Clínic, 'ISGlobal, Barcelona \\ Centre for International Health \\ Research (CRESIB), Hospital Clínic, \\ Universitat de Barcelona, Barcelona, \\ ${ }^{7}$ Epidemiology and Assessment Unit, \\ Fundació Parc Taulí, Universitat \\ Autònoma de Barcelona, Sabadell, \\ ${ }^{8}$ Health Services Research on Chronic \\ Diseases Network-REDISSEC, \\ Galdakao, Spain \\ *These authors contributed equally \\ to this work
}

Correspondence: Miguel Gallego Department of Respiratory Medicine, Hospital de Sabadell, Institut Universitari Parc Taulí-UAB, Parc Tauli I, Sabadell, Barcelona, 08208, Spain

Tel +34937231010

Fax +34937I7 5067

Emailmgallego@tauli.cat
Background: C-reactive protein (CRP) measurement has proven valuable for detecting exacerbations, but its usefulness in predicting etiology remains controversial. Likewise, its potential value as a marker of severity, which is well established in patients with pneumonia, remains unproven in chronic obstructive pulmonary disease (COPD) exacerbations.

Methods: A cohort study of 118 patients with severe COPD and acute infectious exacerbations were included and followed up over 1 year. Episodes of exacerbations meeting Anthonisen's criteria type I-II were evaluated, analyzing the etiology and inflammatory response as measured by CRP in blood.

Results: A total of 380 episodes were recorded. Full microbiological analysis was available in 265 samples. Haemophilus influenzae was the most commonly isolated bacteria and rhinovirus the most common virus. Median CRP levels from the 265 episodes were higher in the cases with positive cultures for bacteria $(58.30 \mathrm{mg} / \mathrm{L}$, interquartile range [IQR] $21.0-28.2)$ than in episodes only positive for viruses $(37.3 \mathrm{mg} / \mathrm{L}, \mathrm{IQR} 18.6-79.1)$ and cases negative for any microorganism (36.4 mg/L, IQR 10.8-93.7) $(P<0.014)$. H. influenzae and Streptococcus pneumoniae reached the highest CRP levels of $74.5 \mathrm{mg} / \mathrm{L}$ (IQR 23.9-167.9) and $74.1 \mathrm{mg} / \mathrm{L}$ (IQR 42.0-220.7), respectively. In the 380 exacerbations studied, $227(\sim 60 \%)$ were community-managed, while $153(\sim 40 \%)$ required hospital admission. In the multivariate analysis to assess the influence of inflammatory response on exacerbation severity, baseline hypercapnia (odds ratio [OR]: 2.70, 95\% confidence interval [CI]: 1.46-4.9) and CRP levels $>100 \mathrm{mg} / \mathrm{L}$ (OR: $4.23,95 \% \mathrm{CI}$ : 2.12-8.44) were independent predictors after adjustment for baseline characteristics.

Conclusion: CRP level was higher in bacterial infections, especially when $H$. influenzae and $S$. pneumoniae were isolated. CRP values $>100 \mathrm{mg} / \mathrm{L}$ were associated with a fourfold increased risk of hospital admission. Therefore, CRP blood levels may be a useful biomarker in the management of exacerbations appearing in patients with severe disease.

Keywords: COPD exacerbations, C-reactive protein, viruses, hospital admission

\section{Introduction}

In the natural history of chronic obstructive pulmonary disease (COPD), exacerbations have a significant impact on mortality, ${ }^{1}$ especially in those who require hospital admission. Indeed, exacerbations become more frequent and more severe as the severity of COPD increases. ${ }^{2}$ Although exacerbations have multiple causes, an infectious etiology is by far the most frequent, with figures up to $78 \%$ for hospital-admitted COPD patients. ${ }^{3}$ Bacterial infections account for one-half of the acute episodes, while respiratory viruses are identified in more than one-quarter, with rhinovirus (RV) and influenza being the most commonly detected viral pathogens. Microbiological studies 
have identified change in sputum color and purulence as good surrogate markers for bacterial infection, ${ }^{4,5}$ while the detection of viruses in exacerbations is only marginally associated with the appearance of changes in the characteristics of sputum. ${ }^{6,7}$ Both respiratory bacteria and viruses are able to produce major local and systemic inflammatory responses, and biomarkers such as C-reactive protein (CRP) have been extensively studied and used as an alternative test to diagnose bacterial infections in both COPD and pneumonia. ${ }^{8,9}$ Likewise, in stable COPD, CRP levels have been examined as a marker of bacterial colonization and/or subclinical infection ${ }^{10}$ but in studies of exacerbated COPD patients, including viral etiology, they have proven unable to distinguish virus-associated exacerbations from others. ${ }^{7}$ In fact, a recent study by Clark et al demonstrated a higher level of CRP in exacerbations due to viruses than in those with positive cultures for bacteria. ${ }^{11}$

Few studies have evaluated the usefulness of CRP as a predictor of the severity of acute episodes. Studies that have suggested that high CRP levels are a marker of exacerbation in COPD have not demonstrated its value for the identification of episodes severe enough to require admission. ${ }^{12}$ In severe COPD outpatients, studies of CRP are scarce, and the relationship between microorganisms and the severity of exacerbations is not fully understood.

The aim of the present study was to identify the causative microorganism (either bacterium or virus) in Anthonisen type $\mathrm{I}-\mathrm{II}^{13}$ exacerbation episodes in a cohort of severe COPD outpatients. We evaluated the systemic inflammatory response as measured by CRP blood levels and assessed their impact on the severity of the episode, measured as the need for hospital admission.

\section{Materials and methods}

Outpatients from a Severe COPD Cohort regularly attending a Respiratory Diseases Day Care Unit for scheduled and exacerbation visits from $2005^{14,15}$ were the target population for the present study. Patients included in the cohort had scheduled visits and received education on self-care of the disease and a personal action plan, with unscheduled visits when exacerbation symptoms appeared, as described elsewhere. ${ }^{14}$ Inclusion criteria for the study were a baseline forced spirometry showing a forced expiratory volume in 1 second $\left(\mathrm{FEV}_{1}\right)<50 \%$ of the reference value and the report of three or more exacerbations in the previous year. Age $<40$ years, previous diagnosis of asthma, cystic fibrosis, cancer, bronchiectasis diagnosed from a previous chest $\mathrm{X}$-ray, and chronic treatment with oral corticosteroids, immunosuppressive drugs, or long-term systemic or inhaled antibiotic therapy were exclusion criteria for the study. Ethical permission for the study was obtained from the Sabadell Hospital Ethics Committee and written informed consent was given by each participant on enrollment.

\section{Clinical variables}

At baseline, smoking history, severity of the disease, Bodymass, airflow Obstruction, Dyspnea, and Exercise index, ${ }^{16}$ comorbidities (Charlson Comorbidity Index), ${ }^{17}$ and use of long-term home oxygen therapy was recorded. COPD was defined as a post bronchodilator ratio of $\mathrm{FEV}_{1}$ to forced vital capacity of $<0.7$ according to the Global Initiative for Chronic Obstructive Lung Disease (GOLD) criteria, in a patient with a smoking habit of $>10$ pack-years. ${ }^{18}$ A computed tomography scan was obtained as part of the patient's baseline characterization in order to identify undiagnosed bronchiectasis, grading its extension in accordance with previously reported criteria. ${ }^{14}$

Participants from the Severe COPD Cohort underwent the same scheduled clinical controls performed by the same team of pulmonologists at the respiratory daycare unit. They received regular treatment with long-acting beta-agonists, anticholinergics, and inhaled corticosteroids in accordance with current guidelines, ${ }^{18}$ and attended the unit for unscheduled visits when acute symptoms appeared. All visits were recorded, together with hospitalizations and mortality due to respiratory causes.

Exacerbations suffered by patients from the Severe COPD Cohort participating in the study were the target for the present study. Episodes that required an unscheduled visit at the unit and met more than two Anthonisen's criteria ${ }^{13}$ between January 2005 and March 2008 were considered for the study. In all episodes, acute symptoms were recorded, together with fever, respiratory rate (RR), and upper respiratory symptoms (nasal congestion, increased rhinorrhea, or sore throat). A chest X-ray was performed to rule out pneumonia.

Blood analyses, including blood counts, renal function, electrolytes, CRP levels, and arterial gases, were performed in all exacerbations, and a spontaneous sputum sample was obtained before the administration of antibiotics. Decisions regarding treatment and admission were left to the discretion of attending physicians, and were taken in accordance with international guidelines. ${ }^{18,19}$ Exacerbations were considered severe in the presence of criteria for hospital admission. ${ }^{20}$

Episodes in which prior antibiotic or corticosteroids were administered ( $<5$ days) were excluded from the final analysis. ${ }^{21}$ 


\section{Sputum samples}

Spontaneous sputum samples were collected from each exacerbation and processed within 60 minutes of collection. Murray-Washington criteria were used for the identification and selection of samples representative of bronchial secretions. ${ }^{22}$ Sputum samples graded Murray IV-V were cultured for potentially pathogenic microorganisms (PPMs) in selective media according to standard methods, and cultures were considered positive when PPMs were recovered. ${ }^{23}$

Briefly, samples were vortexed for 30-60 seconds after homogenization with sputolysin and $10 \mu \mathrm{L}$ of the solution obtained was cultured using a calibrated loop in blood agar, blood agar with nalidixic acid, chocolate agar, and McConkey agar plates. All plates were incubated in a $5 \%$ carbon dioxide incubator at $35^{\circ} \mathrm{C}$ (MacConkey agar under aerobic conditions) and read at 18 and 48 hours. Gram-negative and Gram-positive bacteria recognized as agents causing respiratory infections, such as Haemophilus influenzae, Haemophilus parainfluenzae, Streptococcus pneumoniae, Moraxella catarrhalis, Pseudomonas aeruginosa, Staphylococcus aureus, and Enterobacteriaceae, were considered as PPMs. ${ }^{24}$

The number of colony forming units per milliliter of sputum was calculated from the number of colonies obtained and the dilution of the sputum. Bacteriology data are expressed as the total bacterial count in log base 10 .

Viral DNA/RNA was extracted from $200 \mu \mathrm{L}$ of respiratory clinical samples previously liquefied with Sputasol ${ }^{\circledR}$ (Oxoid Limited, Basingstoke, UK) in a $37^{\circ} \mathrm{C}$ water bath for 20 minutes. Then, DNA/RNA was extracted using QIAmp MinElute Virus Spin procedure on the QIAcube ${ }^{\circledR}$ (Qiagen, Hilden, Germany) obtaining $50 \mu \mathrm{L}$ of nucleic acid elute.

A multiplex retrotranscriptase-nested polymerase chain reaction (RT-PCR) assay was used for simultaneous detection of parainfluenza virus $(1,2,3,4 \mathrm{AB})$, human coronavirus 229E and OC43, enterovirus, RV, influenza virus A, B, C, respiratory syncytial virus (RSV), and adenovirus following the procedure described by Coiras et al..$^{25}$

\section{Statistical analysis}

Data were analyzed using GraphPad PRISM version 7.0 (GraphPad Software Inc., San Diego, CA, USA) and PASW Statistics version 21 (SPSS Inc., Chicago, IL, USA). Results for categorical variables were expressed as absolute and relative frequencies, and continuous variables were expressed as mean values and standard deviations (SDs) or median and interquartile ranges (IQRs) when distribution was non-normal.
We used a generalized estimating equation (GEE) logistic model with an exchangeable within-patient correlation structure and robust standard errors to account for individual patients with multiple exacerbations. The GEE logistic regression model was used to analyze factors associated with hospital admission. In the model we included all patient-related covariates that were judged a priori to be clinically relevant and those with a $P$-value $<0.1$. Correlations between pairs of predictors were examined to ensure the absence of multicollinearity in the model. Odds ratio and their confidence intervals were estimated with $95 \%$ confidence. For all GEE analyses, a univariate analysis was carried out first.

\section{Results}

\section{Patient characteristics}

One hundred eighteen patients from the Severe COPD Cohort met the inclusion criteria for the study. The study population was predominantly male, with a mean (SD) age of 69 (8) years, and over half of the cases were classified as GOLD IV. Their baseline clinical characteristics are shown in Table 1. A total of 386 sputum samples were obtained during exacerbations meeting $\geq 2$ Anthonisen criteria in the follow-up period, with a median exacerbation rate of 1.70 (IQR 0.90-2.66) episodes per year. A single exacerbation was reported in 44 patients, whereas 24 presented two and

Table I Baseline and clinical characteristics of II 8 patients with severe COPD and acute infectious exacerbations

\begin{tabular}{ll}
\hline Subjects & $\mathbf{N}=\mathbf{I} \mathbf{I 8}$ \\
\hline Follow-up (days) & $\mathrm{I}, 003 \pm 306$ \\
Age (years) & $69.5 \pm 8.2$ \\
Current smoking & $13(\mathrm{II})$ \\
Pack-years & $63.3 \pm 31.9$ \\
Alcohol abuse $>80 \mathrm{~g} / \mathrm{L}$ & $3(2.5)$ \\
Influenza vaccination & $105(89)$ \\
Pneumococcus vaccination & $57(48.3)$ \\
Body mass index $\left(\mathrm{kg} / \mathrm{m}^{2}\right)$ & $27.5 \pm 4.6$ \\
FEV, post-BD $(\mathrm{L})$ & $0.97 \pm 0.3$ \\
FEV, post-BD $(\%$ predicted) & $34 \pm \mathrm{II}$ \\
GOLD stage IV & $7 \mathrm{I}(60)$ \\
BODE score & $5.1 \pm 1.6$ \\
Basal hypercapnia & $49(41.5)$ \\
LTOT & $50(42.4)$ \\
Charlson Comorbidity Index & $4.13 \pm 1.5$ \\
Bronchiectasis & $56(47.5)$ \\
\hline
\end{tabular}

Notes: Data are presented as mean \pm SD or $n$ (\%), unless otherwise stated. Hypercapnia defined as $\mathrm{PaCO}_{2}>5.9 \mathrm{Kpa}$.

Abbreviations: BODE, Body-mass index, airflow Obstruction, Dyspnea, and Exercise index; COPD, chronic obstructive pulmonary disease; $F E V_{1}$, forced expiratory volume in I second; GOLD, Global Initiative for Chronic Obstructive Lung Disease; LTOT, long-term oxygen therapy; m, mean; post-BD, post bronchodilator; $\mathrm{SD}$, standard deviation. 
the remaining 50 presented three or more. Six episodes were excluded from further analysis due to corticosteroid treatment and/or antibiotic treatment in the last 5 days before the current episode. Of the remaining 380 episodes, 227 (60\%) were community-managed, with oral antibiotics and/or corticosteroids ( $96.5 \%$ and 59\%, respectively), while 153 episodes $(40 \%)$ were considered severe and required hospital admission.

\section{Microbiology}

From a total of 380 sputum samples collected, full microbiological analyses were possible from 265 exacerbations providing samples valid for analysis according to MurrayWashington criteria and harboring enough material to perform RT-PCR (Figure 1). Pathogenic bacteria were cultivated from 167 (63\%) of the episodes, with $H$. influenzae $(\mathrm{n}=66)$, S. pneumoniae $(\mathrm{n}=28), M$. catarrhalis $(\mathrm{n}=28)$, and $P$. aeruginosa $(\mathrm{n}=28)$ being the most frequently recovered species. In 96 samples (36\%), viruses were detected; $\mathrm{RV}$ was the most common (56) followed by parainfluenzae (17), influenza virus (9), coronavirus (7), RV (5), and adenovirus (2). Viruses were identified from 45 of the
98 samples with negative cultures for bacteria (45.9\%) and from 51 of the 167 exacerbations with cultures showing bacterial infection $(30.5 \%)$, which were accordingly considered as coinfections. In these episodes, the relationships between bacterial type and viruses detected did not show statistical significance $(P=0.9)$.

Seasonal virus distribution demonstrated a higher prevalence of virus infections during fall and winter. RVs were present at all times of year, while parainfluenza, influenza, and RSV were predominately isolated in fall or winter (Figure 2).

\section{CRP levels and etiology of exacerbations}

Median CRP levels from the 265 episodes with full microbiological analyses were higher in cases with positive cultures for bacteria (58.3 mg/L, IQR 21.0-128.2) than in episodes only positive for viruses (37.3 mg/L, IQR 18.6-79.1) and cases negative for any microorganism $(36.4 \mathrm{mg} / \mathrm{L}$, IQR 10.8-93.7) $(P<0.014)$. In bacterial infections, CRP reached the highest levels in exacerbations due to S. pneumoniae (74.1, IQR 42.0-220.7) and H. influenzae (74.5, IQR 23.9-167.9) in comparison with episodes related

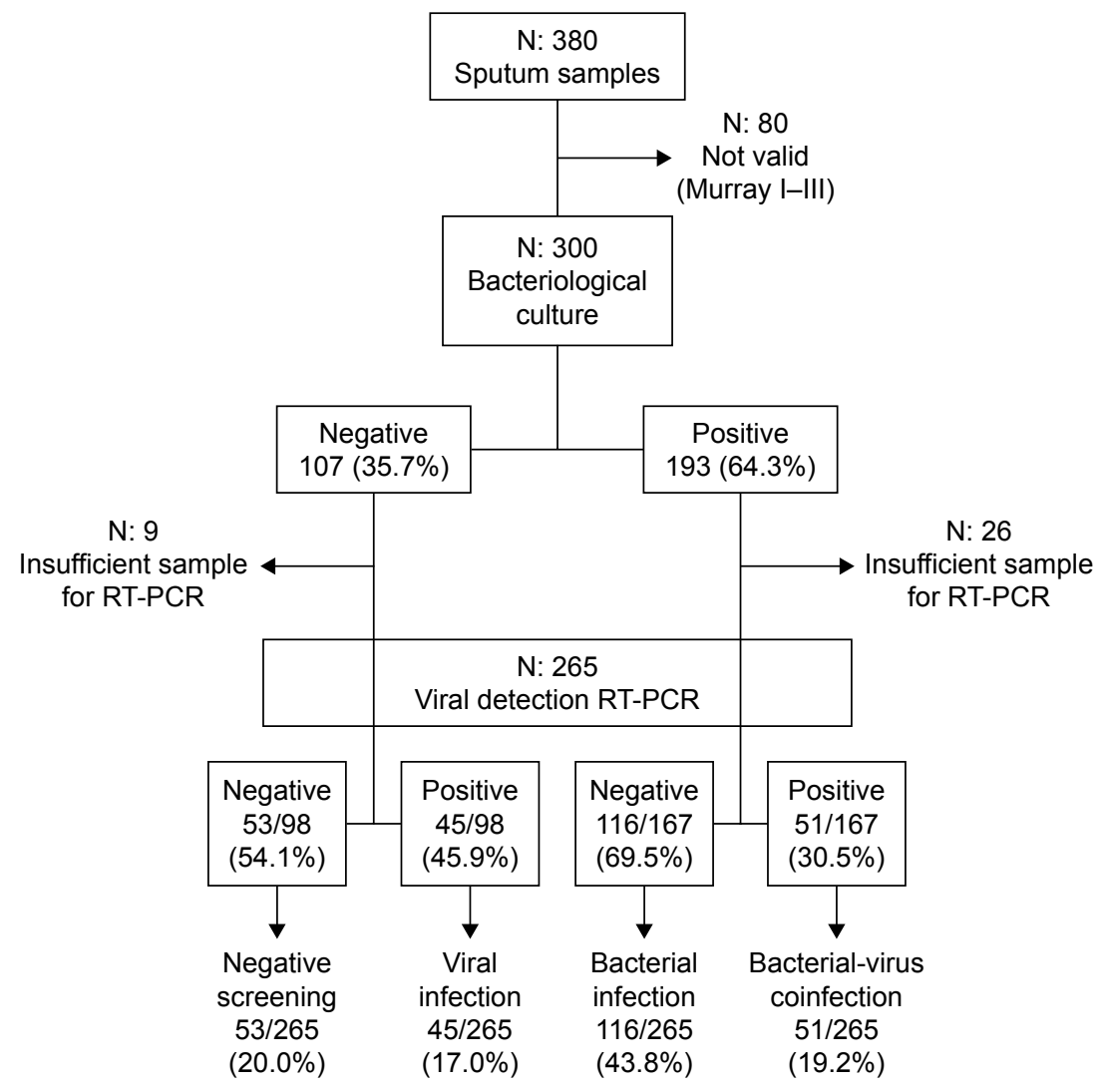

Figure I Flowchart for sputum samples included in the study. Abbreviation: RT-PCR, retrotranscriptase-nested polymerase chain reaction. 


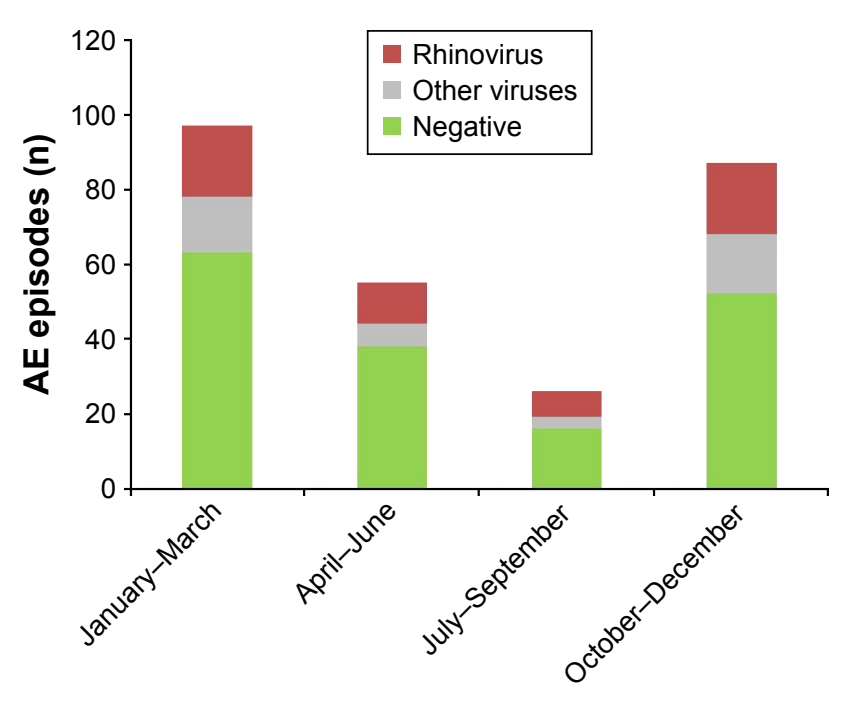

Figure 2 Seasonal pattern of virus detection in episodes of acute exacerbation (AE) of COPD (265 episodes analyzed).

Abbreviation: COPD, chronic obstructive pulmonary disease.

to $P$. aeruginosa (45.2, IQR 11.1-70.1) or infections due exclusively to viruses (37.3, IQR 18.6-79.1) (Table 2). CRP was not related with bacterial load except for $S$. pneumoniae, in which a significant correlation was observed (Figure 3). Episodes due to $S$. pneumoniae also reported fever (15, $56 \%)$ and required hospital admission $(17,60.7 \%)$ more frequently than other microorganisms $(P=0.061$ and 0.002 , respectively). Self-reported upper airway symptoms were similar across the groups (Table 2).

\section{CRP and exacerbation severity}

In the 380 exacerbations studied, significant differences in CRP levels were found between community-attended episodes (37.3 mg/L, IQR 12.8-82.7) and hospitalized episodes (67.4 mg/L, IQR 27.0-189.0).

Other markers of exacerbation severity such as RR, $\mathrm{SaO}_{2}, \mathrm{PaO}_{2}$, and $\mathrm{PaCO}_{2}$ were also associated with the need for hospital admission (Table 3). The increase in CRP was significantly associated with increases in RR and leukocytes, and a fall in $\mathrm{SaO}_{2}(r h o=0.143 ; P=0.012, r h o=0.270 ; P<0.01$ and $r h o=-0.185 ; P<0.01$, respectively). In the GEE model for assessing the influence of inflammatory response on exacerbation severity, CRP emerged as predictive, along with long-term oxygen therapy and baseline hypercapnia. When adjusted for clinical variables and comorbidities, both basal hypercapnia and CRP remained in the model, with a fourfold risk of hospital admission when the CRP level was $>100 \mathrm{mg} / \mathrm{L}$ (Table 4 ).

\section{Discussion}

In a well-characterized cohort of severe COPD patients with Anthonisen type I-II exacerbations, systemic inflammation, as measured by CRP, was associated with a bacterial etiology (mainly S. pneumoniae or H. influenzae), and with bacterial load when $S$. pneumoniae was the causative agent. CRP, additionally, was a good predictor of the severity of the exacerbations; patients with CRP levels $>100 \mathrm{mg} / \mathrm{L}$ presented a fourfold increase in hospitalization. Basal hypercapnia emerged as an additional predictor of admission in the cohort. Thus, CRP emerges as a good biological marker for the identification of severe exacerbations in COPD patients with advanced disease, mainly related to bacterial infections due to $S$. pneumoniae and $H$. influenzae.

The prevalence of infection in severe COPD outpatients in our study was $80 \%$, with figures $>60 \%$ for bacteria and $\sim 40 \%$ for viruses, one-half of them as coinfections with pathogenic bacteria. These data are similar to those obtained in other studies that have focused on patients requiring hospitalization due to the severity of the episode, ${ }^{26,27}$ suggesting that this etiologic pattern characterizes severe COPD exacerbations. H. influenzae was the most frequently recovered bacteria in the present study and was the cause of one-quarter of the

Table 2 Clinical characteristics and inflammatory biomarkers by microorganism $(\mathrm{N}=265)^{*}$

\begin{tabular}{|c|c|c|c|c|c|c|c|c|}
\hline & $H I, n=66$ & $\mathrm{SP}, \mathrm{n}=\mathbf{2 8}$ & $M C, n=28$ & PS, $n=28$ & Other, $n=17$ & $\begin{array}{l}\text { Negative, } \\
n=53\end{array}$ & $\begin{array}{l}\text { Only virus, } \\
n=45\end{array}$ & $P$-value ${ }^{\$}$ \\
\hline Fever $(\%)^{+}$ & 40 & 56 & 36 & 11.5 & 33.3 & 41.7 & 34.9 & 0.061 \\
\hline UAS (\%) & 26.2 & 17.9 & 28.6 & 5.6 & 6.0 & 18.4 & 25.6 & 0.315 \\
\hline $\begin{array}{l}\text { WBC count, } \\
\text { median (IQR) }\end{array}$ & $\begin{array}{l}10,480 \\
(8,560-12,970)\end{array}$ & $\begin{array}{l}\text { II,500 } \\
(9,670-\mid 4,740)\end{array}$ & $\begin{array}{l}9,420 \\
(7,862-9,420)\end{array}$ & $\begin{array}{l}8,985 \\
(7,927-10,365)\end{array}$ & $\begin{array}{l}9,250 \\
(6,740-13,250)\end{array}$ & $\begin{array}{l}10,435 \\
(8,487-\mid 1,427)\end{array}$ & $\begin{array}{l}9,585 \\
(7,230-11,355)\end{array}$ & 0.039 \\
\hline $\begin{array}{l}\text { CRP }(\mathrm{mg} / \mathrm{L}) \\
\text { median (IQR) }\end{array}$ & $\begin{array}{l}74.50 \\
(23.90-167.90)\end{array}$ & $\begin{array}{l}74.10 \\
(42.0-220.7)\end{array}$ & $\begin{array}{l}38.10 \\
(20.60-95.40)\end{array}$ & $\begin{array}{l}45.20 \\
(11.10-70.10)\end{array}$ & $\begin{array}{l}51.90 \\
(23.60-166.0)\end{array}$ & $\begin{array}{l}36.40 \\
(10.80-93.70)\end{array}$ & $\begin{array}{l}37.30 \\
(18.60-79.10)\end{array}$ & 0.026 \\
\hline Hospital admission (\%) & 47 & 60.7 & 21.4 & 57 & $4 I .1$ & 22.6 & 37.8 & 0.002 \\
\hline
\end{tabular}

Notes: *Primary pathogen included; when more than two bacteria were isolated, the higher bacterial load was analyzed. ${ }^{+}$Missing values: I in $\mathrm{HI}$ group, I in SP, 3 in MC, 2 in PS, 2 in Other, 5 in Negative, and 2 in Only virus. \#Missing values: I in HI, 4 in Negative, and 2 in Only virus. ${ }^{\$}$ Chi-squared across all groups (median test in case of continuous variables).

Abbreviations: CRP, C-reactive protein; HI, Haemophilus influenzae; IQR, interquartile range; MC, Moraxella catarrhalis; PS, Pseudomonas aeruginosa; SP, Streptococcus pneumoniae; UAS, upper airway symptoms; WBC, white blood cell. 


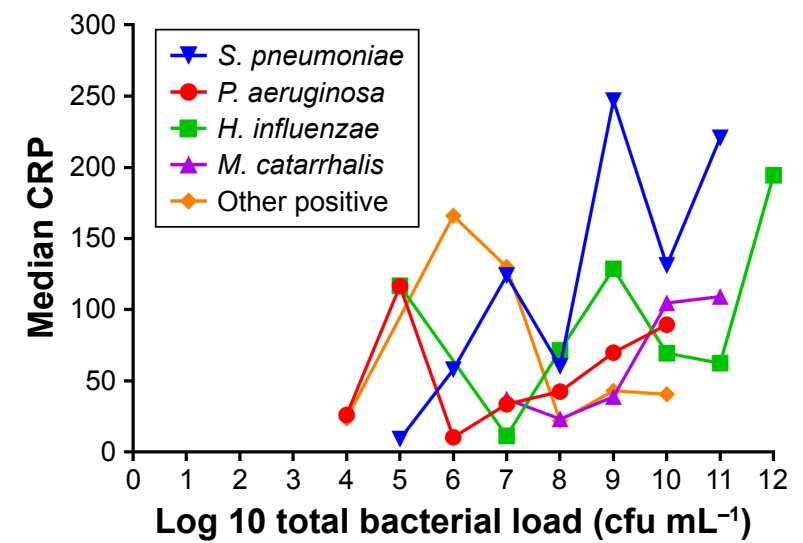

Figure 3 Relationship between bacterial load and CRP (Spearman's correlation coefficient $r$ ho $=0.92 ; P=0.006$ in exacerbations due to $S$. pneumoniae).

Abbreviations: cfu, colony forming units; CRP, C-reactive protein; $H$. influenzae, Haemophilus influenzae; M. catarrhalis, Moraxella catarrhalis; P. aeruginosa, Pseudomonas aeruginosa; S. pneumoniae, Streptococcus pneumoniae.

exacerbations, followed by $S$. pneumoniae, M. catarrhalis, and $P$. aeruginosa. Consistent with other reports, RVs were the most frequently detected virus in our study, in $30 \%$ of the cases as a coinfection with pathogenic bacteria. ${ }^{27,6}$

CRP levels in peripheral blood were clearly related to the etiology of the exacerbation in the study population, with the highest figures for $S$. pneumoniae and $H$. influenzae and a statistically significant relationship between bacterial load and blood levels of this inflammatory marker for S. pneumoniae. The systemic impact of this PPM has been assessed in patients with pneumonia; it is related to severity and prognosis ${ }^{9,28}$ and is determined by a host-pathogen interaction favored by the C-polysaccharide of the pneumococcal cell wall. ${ }^{29}$ The inflammatory power of $H$. influenzae in the bronchial tree is well known and has been related to microbial load, ${ }^{10}$ but the systemic effect of this PPM has been studied only marginally. The present results confirm that bronchial infections due to $H$. influenzae have a clear systemic effect in severe COPD patients, as measured by CRP levels in peripheral blood, equivalent to the effect found in S. pneumoniae-related exacerbations. This finding is clinically significant, because $H$. influenzae is the most prevalent cause of exacerbation in these patients; infections by $H$. influenzae and $S$. pneumoniae were the cause of nearly one-half of the episodes. In contrast, virus detection was associated with lower CRP levels and severity. Our results are at odds with those of previous studies that have reported higher levels of serum CRP in patients with virus-induced exacerbations. ${ }^{6,11}$ The differences are probably due to the characteristics of the episodes reported here, consisting of exacerbations that appear in the follow-up of a cohort of severe COPD outpatients. Previous studies have focused on severe exacerbations requiring hospitalization and have thus missed milder episodes that may be partially related to viruses and probably evolve with lower CRP levels.

Unfortunately, as previously reported, ${ }^{7}$ CRP levels were unable to predict etiology due to the overlapping of levels between the different microorganisms.

In our study, CRP levels were clearly related to the need for hospitalization; with CRP $>100 \mathrm{mg} / \mathrm{L}$, the probability of admission rose more than fourfold. These high CRP figures were mainly related to bacterial infections by $S$. pneumoniae and $H$. influenzae. This relationship did not depend on the covariates assessed and supports a role for this inflammatory marker in the management of exacerbations appearing in severe COPD outpatients; however, in previous studies, it did not prove valuable in predicting outcome. ${ }^{12,30}$ Our study suggests similarities with pneumonia in relation to the significance of CRP for the management of these entities. In fact, a cutoff $>100 \mathrm{mg} / \mathrm{L}$ has been associated with adverse outcomes ${ }^{28}$ and demonstrated a predictive ability for selecting patients requiring intensive care unit (ICU) admission. ${ }^{31}$ Similar values of CRP have been reported in COPD exacerbations for selecting patients requiring ICU admission, although the number of patients included $(n=64)$ was too small to draw conclusions. ${ }^{32}$

Our study also underlined the importance of baseline hypercapnia as a marker of severity in acute episodes, in

Table 3 Markers of exacerbation severity $(\mathrm{N}=380)$

\begin{tabular}{|c|c|c|c|c|}
\hline & Reference values & Community-managed, $n=227$ & Hospital admitted, $n=\mid 53$ & $P$-value* \\
\hline CRP & $<5 \mathrm{mg} / \mathrm{L}$ & 37.3 (12.8-82.7) & $67.4(27.0-189.0)$ & $<0.0001$ \\
\hline WBC count & $4,000-11,000$ & $9,900(7,860-11,460)$ & $10,030(8,500-14,002)$ & 0.001 \\
\hline $\mathrm{RR}$ & $12-16$ breath $/ \mathrm{min}$ & $24(20-28)$ & $26(24-30)$ & 0.002 \\
\hline $\mathrm{SaO}_{2}$ & $96 \%-100 \%$ & $94(92-95)$ & $89(85-92)$ & $<0.0001$ \\
\hline $\mathrm{PaO}_{2}^{+}$ & $10.6-13.3 \mathrm{KPa}$ & $7.9(7.3-8.6)$ & $7.0(6.2-7.6)$ & 0.002 \\
\hline $\mathrm{PaCO}_{2}^{+}$ & $4.6-5.9 \mathrm{KPa}$ & $5.7(5.2-6.6)$ & $6.2(5.4-7.5)$ & 0.001 \\
\hline $\mathrm{pH}^{+}$ & $7.35-7.45$ & $7.42(7.40-7.44)$ & 7.41 (7.39-7.44) & 0.443 \\
\hline
\end{tabular}

Notes: *Univariate generalized estimating equation. ${ }^{+}$Only obtained in 197 episodes. Data presented as median (interquartile range).

Abbreviations: CRP, C-reactive protein; IQR, interquartile range; min, minutes; RR, respiratory rate; WBC, white blood cell. 
Table 4 Analysis of factors associated with hospital admission. Results of univariate and multivariate GEE

\begin{tabular}{|c|c|c|c|c|}
\hline & OR $(95 \% \mathrm{Cl})$ & $P$-value & OR $(95 \% \mathrm{Cl})$ & $P$-value \\
\hline GOLD stage IV & $1.28(0.75-2.18)$ & 0.36 & - & - \\
\hline Charlson Comorbidity Index & $1.15(0.95-1.40)$ & 0.14 & $1.12(0.95-1.32)$ & 0.15 \\
\hline Bronchiectasis & $1.39(0.78-2.47)$ & 0.26 & - & - \\
\hline BODE & $1.13(0.93-1.37)$ & 0.21 & - & - \\
\hline LTOT & $1.89(1.08-3.32)$ & 0.02 & $1.14(0.6 \mathrm{I}-2.13)$ & 0.67 \\
\hline Baseline hypercapnia & $2.69(1.56-4.64)$ & $<0.000$ I & $2.70(1.46-4.9)$ & 0.01 \\
\hline \multicolumn{5}{|l|}{$\mathrm{CRP}(\mathrm{mg} / \mathrm{L})$} \\
\hline$<18.6$ & $\mathrm{I}$ & & $\mathrm{I}$ & \\
\hline $18.7-47.7$ & $1.74(0.91-3.33)$ & 0.09 & $1.64(0.85-3.15)$ & 0.13 \\
\hline $47.8-100$ & $2.56(1.25-5.24)$ & 0.01 & $2.21(1.05-4.68)$ & 0.03 \\
\hline$>100$ & $4.44(2.25-8.78)$ & $<0.0001$ & $4.23(2.12-8.44)$ & $<0.0001$ \\
\hline
\end{tabular}

Note: CRP data is presented as quartiles.

Abbreviations: BODE, Body-mass index, airflow Obstruction, Dyspnea, and Exercise index; $\mathrm{Cl}$, confidence interval; CRP, C-reactive protein; GEE, generalized estimating equation; GOLD, Global Initiative for Chronic Obstructive Lung Disease; LTOT, long-term oxygen therapy; OR, odds ratio.

agreement with previous studies that have associated this abnormality with survival..$^{33}$ Baseline hypercapnia doubled the risk of hospital admission and it seems reasonable to think that it identified a subgroup of more frail patients, at least in our cohort.

In two studies with exacerbated COPD patients, ${ }^{34,35}$ the addition of arterial blood gas parameters (oxygen and carbon dioxide partial pressures and $\mathrm{pH}$ ) did not improve the prediction of mortality during hospitalization, but was closely related with need for admission. However, no baseline data were recorded in these studies.

\section{Limitations}

The present study has some limitations related to patient selection. Participants were from a severe COPD population regularly attending a respiratory daycare unit, and our results cannot be extrapolated to the COPD population as a whole. The number of episodes recorded in the different patients also varied widely. Even though we used a GEE approach to overcome this problem, we cannot rule out a possible overrepresentation of a particular subset of patients who may be more susceptible to specific microorganisms.

Finally, infections with uncommon respiratory viruses such as metapneumovirus and bocavirus were not evaluated in our study, and the true prevalence of virus infection may therefore be slightly underestimated.

\section{Conclusion}

In conclusion, this study demonstrated a high prevalence of bacterial infection, mainly due to H. influenzae, S. pneumoniae, $M$. catarrhalis, and $P$. aeruginosa in exacerbations appearing in severe COPD outpatients. The prevalence of viral infections was significantly lower. Systemic inflammation identified through CRP blood levels was higher in bacterial infections, mainly when $H$. influenzae and $S$. pneumoniae were the cause, and high figures for this inflammatory biomarker were related to the severity of the episode. The findings suggest that CRP blood levels may be a useful biomarker in the management of exacerbations appearing in these severe patients.

\section{Acknowledgments}

We thank Michael Maudsley for providing an outline for this manuscript and support in editing and journal styling.

This work has received funding from Fundació La Marató TV3 and SOCAP.

\section{Disclosure}

The authors report no conflicts of interest in this work.

\section{References}

1. Soler-Cataluña JJ, Martínez-García MA, Román Sánchez P, Salcedo E, Navarro M, Ochando R. Severe acute exacerbations and mortality in patients with chronic obstructive pulmonary disease. Thorax. 2005; 60(11):925-931.

2. Hurst JR, Vestbo J, Anzueto A, et al; Evaluation of COPD Longitudinally to Identify Predictive Surrogate Endpoints (ECLIPSE) Investigators. Susceptibility to exacerbation in chronic obstructive pulmonary disease. N Engl J Med. 2010;363(12):1128-1138.

3. Miravitlles M, Anzueto A. Role of infection in exacerbations of chronic obstructive pulmonary disease. Curr Opin Pulm Med. 2015; 21(3):278-283.

4. Stockley RA, O'Brien C, Pye A, Hill SL. Relationship of sputum color to nature and outpatient management of acute exacerbations of COPD. Chest. 2000;117(6):1638-1645.

5. Miravitlles M, Kruesmann F, Haverstock D, Perroncel R, Choudhri SH, Arvis $\mathrm{P}$. Sputum colour and bacteria in chronic bronchitis exacerbations: a pooled analysis. Eur Respir J. 2012;39(6):1354-1360.

6. Seemungal T, Harper-Owen R, Bhowmik A, et al. Respiratory viruses, symptoms, and inflammatory markers in acute exacerbations and stable chronic obstructive pulmonary disease. Am J Respir Crit Care Med. 2001; 164(9):1618-1623. 
7. Kherad O, Kaiser L, Bridevaux PO, et al. Upper-respiratory viral infection, biomarkers, and COPD exacerbations. Chest. 2010;138(4): 896-904.

8. Miravitlles M, Moragas A, Hernández S, Bayona C, Llor C. Is it possible to identify exacerbations of mild to moderate COPD that do not require antibiotic treatment? Chest. 2013;144(5):1571-1577.

9. Krüger S, Ewig S, Papassotiriou J, et al. Inflammatory parameters predict etiologic patterns but do not allow for individual prediction of etiology in patients with CAP: results from the German competence network CAPNETZ. Respir Res. 2009;10(1):65.

10. Marin A, Monsó E, Garcia-Nuñez M, et al. Variability and effects of bronchial colonisation in patients with moderate COPD. Eur Respir J. 2010;35(2):295-302.

11. Clark TW, Medina MJ, Batham S, Curran MD, Parmar S, Nicholson KG. $\mathrm{C}$-reactive protein level and microbial aetiology in patients hospitalised with acute exacerbation of COPD. Eur Respir J. 2015;45(1):76-86.

12. Hurst JR, Donaldson GC, Perera WR, et al. Use of plasma biomarkers at exacerbation of chronic obstructive pulmonary disease. Am J Respir Crit Care Med. 2006;174(8):867-874.

13. Anthonisen NR, Manfreda J, Warren CP, Hershfield ES, Harding GK, Nelson NA. Antibiotic therapy in exacerbations of chronic obstructive pulmonary disease. Ann Intern Med. 1987;106(2):196-204.

14. Gallego M, Pomares X, Espasa M, et al. Pseudomonas aeruginosa isolates in severe chronic obstructive pulmonary disease: characterization and risk factors. BMC Pulm Med. 2014;14:103.

15. Millares L, Ferrari R, Gallego M, et al. Bronchial microbiome of severe COPD patients colonised by Pseudomonas aeruginosa. Eur J Clin Microbiol Infect Dis. 2014;33(7):1101-1111.

16. Celli BR, Cote CG, Marín JM, et al. The body-mass index, airflow obstruction, dyspnea, and exercise capacity index in chronic obstructive pulmonary disease. $N$ Engl J Med. 2004;350(10):1005-1012.

17. Charlson M, Szatrowski TP, Peterson J, Gold J. Validation of a combined comorbidity index. J Clin Epidemiol. 1994;47(11):1245-1251.

18. From the global strategy for the diagnosis, management and prevention of COPD, Global Initiative for Chronic Obstructive Lung Disease (GOLD); 2013. Available from: http://www.goldcopd.org/. Accessed January 7, 2016.

19. Woodhead M, Blasi F, Ewig S, et al. Guidelines for the management of adult lower respiratory tract infections. Clin Microbiol Infect. 2011; 17(Suppl 6):E1-E59.

20. Celli BR, MacNee W; ATS/ERS Task Force. Standards for the diagnosis and treatment of patients with COPD: a summary of the ATS/ ERS position paper. Eur Respir J. 2004;23(6):932-946.

21. Hurst JR, Donaldson GC, Quint JK, Goldring JP, Baghai-Ravary R, Wedzicha JA. Temporal clustering of exacerbations in chronic obstructive pulmonary disease. Am J Respir Crit Care Med. 2009;179(5): 369-374.
22. Murray PR, Washington JA. Microscopic and bacteriologic analysis of expectorated sputum. Mayo Clin Proc. 1975;50(6):339-344.

23. Balows A, Hausler WJ, Herrmann KL, Isenberg HD, Shadomy HJ, editors. Manual of Clinical Microbiology. 5th Ed. Washington DC: American Society of Microbiology; 1991.

24. Cabello H, Torres A, Celis R, et al. Bacterial colonization of distal airways in healthy subjects and chronic lung disease: a bronchoscopic study. Eur Respir J. 1997;10(5):1137-1144.

25. Coiras MT, Aguilar JC, García ML, Casas I, Pérez-Breña P. Simultaneous detection of fourteen respiratory viruses in clinical specimens by two multiplex reverse transcription nested-PCR assays. J Med Virol. 2004;72(3):484-495.

26. Ko FW, Ip M, Chan PK, et al. A 1-year prospective study of the infectious etiology in patients hospitalized with acute exacerbations of COPD. Chest. 2007;131(1):44-52.

27. Papi A, Bellettato CM, Braccioni F, et al. Infections and airway inflammation in chronic obstructive pulmonary disease severe exacerbations. Am J Respir Crit Care Med. 2006;173(10):1114-1121.

28. Chalmers JD, Singanayagam A, Hill AT. C-reactive protein is an independent predictor of severity in community-acquired pneumonia. Am J Med. 2008;121(3):219-225.

29. Peisajovich AL, Marnell C, Mold C, Du Clos TW. C reactive protein at the interface between innate immunity and inflammation. Exp Rev Clin Immunol. 2008;4(3):379-390.

30. Bozinovski S, Hutchinson A, Thompson M, et al. Serum amyloid A is a biomarker of acute exacerbations of chronic obstructive pulmonary disease. Am J Respir Crit Care Med. 2008;177(3):269-278.

31. Ramírez P, Ferrer M, Martí V, et al. Inflammatory biomarkers and prediction for intensive care unit admission in severe community-acquired pneumonia. Crit Care Med. 2011;39(10):2211-2217.

32. Karadeniz G, Polat G, Senol G, Buyuksirin M. C-reactive protein measurements as a marker of the severity of chronic obstructive pulmonary disease exacerbations. Inflammation. 2013;36(4):948-953.

33. Postma DS, Burema J, Gimeno F, et al. Prognosis in severe chronic obstructive pulmonary disease. Am Rev Respir Dis. 1979;119(3): 357-367.

34. Quintana JM, Esteban C, Unzurrunzaga A, et al. Predictive score for mortality in patients with COPD exacerbations attending hospital emergency departments. BMC Med. 2014;12:66.

35. Vidal S, González N, Barrio I, et al. Predictors of hospital admission in exacerbations of chronic obstructive pulmonary disease. Int J Tuberc Lung Dis. 2013;17(12):1632-1637.
International Journal of COPD

\section{Publish your work in this journal}

The International Journal of COPD is an international, peer-reviewed journal of therapeutics and pharmacology focusing on concise rapid reporting of clinical studies and reviews in COPD. Special focus is given to the pathophysiological processes underlying the disease, intervention programs, patient focused education, and self management protocols.

\section{Dovepress}

This journal is indexed on PubMed Central, MedLine and CAS. The manuscript management system is completely online and includes a very quick and fair peer-review system, which is all easy to use. Visit $\mathrm{http}: / / \mathrm{www}$. dovepress.com/testimonials.php to read real quotes from published authors. 